\title{
LA VIDA EN LAS SIETE PARTIDAS
}

\author{
Hugo Tagle Martínez \\ Profesor de Filosofía e Historia del Derecho \\ Pontificia Universidad Católica de Chile \\ Universidad Central
}

Las Siete Partidas, Libro de las leyes o Fuero de las leyes, como también se le denomina y conoce, es un código elaborado bajo el gobierno de Alfonso X El Sabio, Rey de Castilla y León entre los años 1252 y 1284, redactado entre los años 1256 y 1263 . posiblemente por varios autores para nosotros anónimos, con la probable excepción de Fernando Martínez y Roldán y Jacobo Ruiz, que podrían haber sido sus redactores, actuando todos bajo la inmediata dirección del sabio rey de Castilla y León.

Las Siete Partidas es la obra cumbre del derecho medieval, no sólo castellano o español, sino que europeo y en el derecho ocupa el mismo lugar primero que la Suma Teológica del Santo Tomás de Aquino en Teología y Filosofía y que la Divina Comedia de Dante Alighieri en las letras, obras que son contemporáneas.

Este cuerpo de leyes está dividido, algo arbitrariamente y como lo señala su nombre más conocido, en siete partes y cada una de éstas en títulos y éstos en leyes, siendo en total 182 títulos o materias específicas y 2.718 leyes o artículos, que contienen todo el derecho de la época, como ocurre con los grandes cuerpos jurídicos desde comienzos de la edad media hasta los inicios del siglo XIX, en que se empieza a parcelar el derecho escrito en diferentes cuerpos o códigos.

Por último, digamos, en esta más que breve presentación de las Siete Partidas que, en cuanto a sus normas generales, la partida primera legisla sobre la Iglesia, además de la ley, usos, costumbres y fueros, con los que comienza, a los que dedica los dos primeros títulos; la partida segunda sobre los Emperadores, Reyes y Corte, que constituye lo que hoy día llamamos derecho constitucional, además sobre los estudios, maestros y escolares, lo que expresa la importancia que Alfonso le da a la vida intelectual; la partida tercera sobre la justicia y quién y cómo se la ha de administrar, además de la prescripción, posesión y servidumbre; la partida cuarta del matrimonio y familia, además de los vasallos y siervos, como también de la amistad; la partida quinta sobre los contratos; la partida sexta de las sucesiones y testamentos y por último, la partida séptima, del derecho penal, además de explicar el sentido de algunos términos y de señalar principios generales del derecho. 


\section{La vida}

Antes de entrar a analizar la vida en las Siete Partidas, que es el objetivo de nuestro trabajo, es necesario precisar, aunque sea en general, qué es la vida y de quien o de quienes se predica.

La vida como palabra y como cosa es un término y realidad análogo, pues se predica de varios entes que tienen distinta categoría ontológica, precisamente por poseer la vida en diferente grado de perfección.

La vida es -en Dios- subsistir por si mismo, de tal modo que vida y Dios son términos intercambiables o sinónimos en $\mathrm{El}$ y es así como Dios mismo, encarnado en Nuestro Señor Jesucristo nos dice: "Yo soy la vida" (San Juan 14,6), como también podría habernos dicho la vida soy Yo. La vida es un aspecto, una cara, una perspectiva, un nombre en el que vemos a Dios, que es ser, además, simple, perfecto, infinito, inmutable, eterno y uno, es decir, con un solo término, acto puro, quien, en su operar es creador, ordenador y gobernador.

Además, la vida en Dios es su capacidad de crear a partir de la nada material y formal: Dios es creador, como también legislador y providente.

En conclusión, Dios es la vida en el sentido más pleno, pues no sólo la posee consubstancialmente, siendo El la Vida, sino que además la da a otros entes.

La vida se predica del hombre, que es creatura de Dios hecha a Su imagen y semejanza, esto es, como una reproducción proporcional suya, de tal modo que no siendo la vida, la tiene como un accidente propio, inseparable de él mientras es hombre, o que es lo mismo, está con vida, pero que puede perderla, ya que es mortal, en el doble sentido de muerte natural y sobrenatural.

Además, la vida en el hombre es su capacidad de conocer y querer a Dios, como de conocer y querer al hombre y a todas las cosas; de crear, no como Dios, sino que a partir de la materia, es decir, sólo de transformar la materia, que es manifestación de su dominio sobre ella y capacidad de engendrar a otros hombres, esto es, capacidad de transmitir la vida natural y de comunicar Dios a otros hombres, comunicándoles la vida sobrenatural, como también y por último, de asimilar materias que requiere para subsistir y desarrollarse.

La vida se predica de los animales; en éstos consiste en conocer, pero sólo conocimiento sensible y en convivir - pero no en dominar- con la naturaleza; siendo ellos mismos nada mas que naturaleza; además, en la capacidad de engendrar otros animales de la misma especie, transmitiendo de modo inconsciente e involuntario la vida recibida, como también la capacidad de asimilar materia para subsistir y desarrollarse.

La vida, por último, se predica de las plantas; en éstas consiste solamente en la capacidad de producir otras plantas, transmitiendo la vida general recibida, como también, la capacidad de asimilar materia para subsistir y desarrollarse.

Así entonces, la vida se predica de Dios, del hombre, de los animales y de las plantas; también aceptamos que se predique de los ángeles y espíritus puros, pero sólo por fe, ya que su existencia no es captable por nuestra razón natural.

De lo dicho se concluye en primer lugar, que no se puede dar una definición única de qué es la vida, salvo que se acepte como tal la primordial o vida en Dios o de 
Dios; y en segundo lugar, que hay diferentes grados de vida, que son la total o plena, que es la de Dios; la sobrenatural o religiosa, que es exclusivamente del hombre; la natural, que es en general del hombre, de los animales y de las plantas, en la que distinguimos la intelectual y moral, que es exclusivamente del ser humano; la sensible, que siendo también del hombre, lo es igualmente de los animales y por último la vegetal, que siendo del hombre y de los animales, lo es también y como única vida, de las plantas.

Las Siete Partidas, por ser un libro de derecho, se ocupa únicamente de la vida del hombre, de la sobrenatural y de la natural y de ésta, de la intelectual y moral, además de la sensible o corpórea, que podemos llamar subsistencia, ya que sin ésta -por ser la primera- no es posible la existencia de la vida superior, que es la espiritual intelectual y moral-y religiosa o sobrenatural.

\section{La Vida en las Siete Partidas:}

La primera Partida -que tiene 24 títulos y 516 leyes o artículos- "fabla de todas las cosas que pertenecen a la $\mathrm{Fe}$ Catholica que face al home conocer a Dios por creencia", pues "Dios es comienzo, e medio e acabamiento de todas las cosas e sin El ninguna cosa puede ser, ca por su poder son fechas e por el su saber son gobernadas e por la su bondad son mantenidas" (Prólogo); continúa diciendo que "estas leyes son establecimientos porque los homes sepan vivir bien, e ordenadamente, según el placer de Dios: e otrosi, según conviene a la buena vida deste mundo e a guardar la fe de Nuestro Señor Jesucristo cumplidamente, así como ella es. Otrosi, como vivan los homes unos con otros en derecho e en justicia..." (ley $1^{\text {a }}$.) Más adelante se insiste al decir que "las leyes... face a los homes vivir cada uno como conviene" ( ley $7^{a}$ ).

Después de hablar sobre la ley, usos, costumbres y fueros, esta primera Partida contiene normas religiosas, de fe y eclesiásticas, empezando por la Santa Trinidad, continuando con los sacramentos, para terminar legislando sobre los romeros y peregrinos, en su título XXIV.

Así entonces, esta primera Partida está dedicada -salvo sus dos primeros títulos que se refieren a las materias civiles ya mencionadas- a materias religiosas o de vida sobrenatural, que el derecho del Reino de Castillla, que es civil o político, regula y prescribe, por considerarlas un bien que mejora la vida de sus integrantes.

La segunda Partida -que tiene 31 títulos y 349 leyes- legisla acerca de "los Emperadores, los Reyes, de los otros grandes señores de la tierra, que la han de mantener en justicia e verdad", pues "Nuestro Señor Dios puso otro poder temporal en la tierra con que esto se cumpliese", que es "la fe católica de Nuestro Señor Jesucristo... como se debe creer e honrrar, e guardar" (Prólogo), además, para "mantener e guardar las tierras en justicia"". (Título $1^{\circ}$ ), ya que "el Rey es puesto en la tierra en lugar de Dios, para cumplir la justicia e dar a cada uno su derecho. E por ende lo llamaron corazón e alma del pueblo. Assi como yaze el alma en el corazón del ome, e por ella bive el cuerpo, e se mantiene, assí en el Rey yaze la justicia, que en vida e mantenimiento del pueblo de su Señorío." (ley $5^{\mathrm{a}}$ ).

Concluye esta Partida como el título XXXI, que está dedicado a los "estudios, en que aprenden los saberes, e de los Mestros, e de los escolares." 
Así entonces esta segunda Partida está dedicada a quienes deben proteger la vida, tanto la sobrenatural cuanto la natural, como también a procurar el desarrollo de la vida intelectual o espiritual -que es la vida propia de Dios y que en los hombres, supuesta la existencia como tal, es la primera o más importante -que es la que hace sabios a los hombres, de quienes, que son los maestros principalmente, "los omes e las tierras e los Reynos se aprovechan, e se guardan e se guían por el consejo dellos." (Título XXXI)

La Partida tercera -que tiene 32 títulos y 143 leyes- prolonga en parte a la anterior en cuanto al contenido y función de las personas sobre las que legisla, que es la Justicia y las personas que la administran, que es tarea de la autoridad.

Pues, así como "en la primera Partida deste libro avemos fablado de la Justicia espiritual, que faze al ome ganar el amor de Dios por voluntad: que es la primera espada, porque se mantiene el mundo. E otrosi, en la segunda Partida mostramos de los grandes señores, que la han de mantener generalmente en todas cosas con fortaleza e con poder: que es la otra espada temporal, que fue puesta contra aquellos que la quisiessen embargar o destruir por fuerza errando contra Dios soberviosamente, o contra el Señor temporal, o contra la tierra onde son naturales; queremos en esta tercera partida dezir de la justicia, que se debe fazer ordenadamente por seso e por sabiduría, en demandando e defendiendo cada uno en juizio." (Prólogo).

La justicia, que es virtud que "da e comparte a cada uno su derecho egualmente" (Título I, ley $1^{3}$.) tiene como objetivo un bien muy grande, que es "fazer bevir cuerdamente e sin mala estanza, e sin yerro e con mesura: e aún faze pro a los otros, Ca si son buenos, por ella se fazen mejores rescibiendo galardones por los bienes que fizieron. E otrosi, los malos por ella han de ser buenos, recelándose de la pena que les manda dar por sus maldades. E ella es virtud, porque se mantiene el mundo, faziendo bevir a cada uno en paz, según su estado, e sabor de sí, e teniéndose por abondado de lo que ha" (Título 1, ley $2^{\mathrm{a}}$.)

Los títulos VI, XI, XVI, XVII y XIX protegen el bien que es la verdad, cuyo falseamiento puede afectar a la vida física o espiritual de terceros.

Así, el Título VI, "De los abogados", en su ley $15^{2}$ dispone que "prevaricador en latín tanto quiere dezir en romance como abogado que ayuda falsamente a la parte por quien aboga...t tal abogado como éste deve morir como alevoso... Otrosi dezimos que cuando el abogado fiziere usar a sabiendas a la su parte de falsas cartas o de falsos testigos, que essa misma pena merece."

El Título XI, "De las juras que partes fazen en los pleytos", en su ley $26^{a}$ dice que "mentira jurando alguno en pleytos... non le podemos poner otra pena si non aquella que Dios le quisiere poner. Más... si por su testimonio mentiroso fue alguno muerto o lisiado, que recibe el mismo otra tal pena."

El Título XVI, "De los testigos", en su ley $42^{2}$ dispone que "pena muy grande merecen los testigos que a sabiendas dan falso testimonio contra otro, o que encubren la verdad... Mas otorgamos por esta ley lleno poderío a todos los judgadores que han poder de fazer justicia, que cuando entendieren que los testigos que aduzen ante ellos van desvariando sus palabras e cambiándolas, si fueren viles omes aquellos que esto fizieren, que les puedan tormentar, de guisa que puedan sacar la verdad dellos..." 
EI Título XVII, "De los pesqueridores...", en su ley $12^{\text {a }}$ dispone que "las penas que merecen los pesqueridores... dezimos que debe aver tal pena en el cuerpo, e en el aver qual ovo devía aver aquel contra quien fuesse fecha la pesquisa falsa."

EI Título XIX, "De los escribanos..." en su ley $16^{3}$ dispone que "falsedad faziendo escribano de la Corte del Rey en carta o privilegio, deve morir por ello. Si el escribano de la ciudad fiziere alguna carta falsa o fiziera falsedad en juicio... devenle cortar la mano con que la fizo..."

Así entonces la partida tercera defiende la vida social, la que para ser tal ha de ser ordenada o moral, orden o moral que produce la paz.

La Partida cuarta -que tiene 27 títulos y 256 leyes-, legisla entre otras materias, que son el matrimonio y las vinculaciones entre los hombres, sobre el "estado de los omes", en el título XXIII y sobre la amistad, en el Título XXVII.

En el Título XXIII, sobre "el estado de los omes", dispone que "el estado de los omes e la condicion dellos se departe en... nascidos o por nascer" (Prólogo), con lo que señala que existe el hombre antes del nacimiento.

Por su parte, la ley $3^{a}$ dispone que "demientra que estuviese la criatura en el vientre de su madre, toda cosa que se faga o se diga, a pro della, aprovechase ende, bien assi como si fuesse nascida; más lo que fuesse dicho o fecho a daño de su persona, o de sus cosas, non le empesce."

Así entonces, para las Siete Partidas hay persona humana - hay vida humana- a partir del momento de la concepción, como se debe concluir de una natural interpretación del texto citado, sobre todo si se complementa dicho texto con lo dispuesto por la ley $4^{a}$, que dice que "lo más que la mujer preñada puede traer la criatura en el vientre son diez meses", con lo que se establece con claridad que el comienzo de la existencia de la persona humana se inicia, como máximo, diez meses antes del parto.

En virtud de lo dispuesto o reconocido por la ley con respecto al comienzo de la existencia de la persona humana -que se adelanta en siglos a lo sostenido por la filosofía y últimamente por la ciencia- la ley $8^{a}$ del Título VIII de la Partida séptima, dispone que "la muger preñada que beviere yerbas a sabiendas, o otra cosa qualquiera, con que echasse de si la criatura... deve morir por ello" y la misma pena se aplica al marido o a otro hombre que provocase el aborto.

En el Título XXVIII, que es el último de esta Partida, legisla sobre la amistad, "una virtud que es buena en sí, e provechosa a la vida de los omes: e ha logar propriamente, quando aquel que ama, es amado del otro a quien ama, ca de otra guisa non seria verdadera amistad". (ley $1^{2}$ )

La Partida quinta - que tiene 15 Títulos y 374 leyes- "fabla de los empréstitos, e de las vendidas, e de las compras, e de los cambios, e de todos los otros pleytos e posturas que fasen los omes entre si, de cual natura quier que sean", la que por referirse a cosas que los hombres intercambian, no contiene precepto alguno que tenga por objeto la vida, de tal manera que la pasamos de largo, sin detenernos en ella.

La Partida sexta -que tiene 19 Títulos y 272 leyes- "fabla de los testamentos, e de las herencias", esto es, no de la vida sino que de las cosas que los hombres "fazen a 
su fin (Prólogo); así entonces, por no contener precepto alguno que se refiera a la vida, pasamos de largo, sin detenernos en ella.

La séptima Partida, por último, -que tiene 34 Títulos y 363 leyes- y que "fabla de las acusaciones, e malfechos que fazen los omes, e de las penas e escarmientos que han por ellos", que en terminología actual es derecho penal, se refiere toda ella a la vida, en todos sus niveles o aspectos, defendiéndola de los ataques que pueda sufrir de los hombres, porque "fechos como estos, que se fazen con sobervia, deven ser escarmentados crudamente, porque los fazedores resciban la pena que merescen, a los que lo oyeren, se espanten, e tomen ende escarmiento, porque se guarden de fazer cosa, porque non resciban otro tal". (Prólogo)

Esta Partida es un largo catálogo de delitos que atentan en contra de bienes determinados, tipificados de acuerdo a la mentalidad del hombre medieval, que muestra, por una parte su capacidad de abstracción y por otra, la realidad de la estructura social y de las penas que sus autores merecen, según, claro está, la importancia que las Siete Partidas le da a los bienes protegidos.

En la exposición que a continuación haremos de los delitos y de sus penas, seguiremos el orden que están en las Siete Partidas, porque refleja, así pensamos, la importancia que le otorga, por una parte, a los bienes protegidos, y por otra, a las personas involucradas en ellos como autores de los delitos.

El título primero, "De las acusaciones que se fazen contra los malos fechos, e de los denunciamientos, e del oficio de judgador que ha de pesquerir los malos fechos", contiene normas procesales del juicio criminal, por tanto sus disposiciones son instrumentales y no substantivas, por lo que sólo lo mencionamos sin comentarlo.

El título segundo, "De las trayciones" dispone que "trayción es uno de los mayores yerros e denuestos en que los omes pueden caer, e tanto la tuvieron por mala los sabios antiguos, que conoscieron las cosas derechamente, que la compararon a la gafedad (lepra); ca, bien assi, como la gafedad es mal que prenden por todo el cuerpo, es desspues que es presa, non se puede tirar nin amelezinar, de manera que pueda guarescer el que la ha. E otrosi, que faze a ome después que es, gafo, sea, apartado e alongado de todos los otros. E sin todo esto, es tan fuerte maletia, que non faze mal al que la ha en si tan solamente, mas aun el linaje que por la liña derecha del descienden, e a los que con el moran."

En cuanto a su definición, dice que "Laesa Majestatis crimen, tanto quiere dezir en romance, como yerro de trayción que faze ome contra la persona del Rey" (ley $1^{\text {a }}$ ). como también, "traer un ome a otro so semejanza de bien a mal." (id)

Este título defiende la vida no sólo del Rey, como también la del Reino, sino que además la lealtad que se le debe, su autoridad, principalmente, ya que considera como traición otras varias actitudes de los súbditos que van en contra de lo que podemos denominar bien común, que representa el Rey y sus inmediatos colaboradores.

En cuanto a la pena, dispone que "qualquier ome, que fiziere alguna cosa de las maneras de trayción que diximos en la ley antes desta, o diere ayuda, o consejo que la fagan, deve morir por ello e todos sus bienes deven ser de la Camara del Rey" (ley $1^{\text {a }}$ ) 
El Título III, "De los rieptos", nos dice que la traición es un delito que puede cometer un hidalgo con otro y la pena que merece quien la comete es también, la de muerte.

El Título VI, "De los enfamados", protege el buen nombre, fama o vida histórica del hombre, que le acompaña como la sombra al sujeto que la proyecta, pero en éste al revés, ya que es el pasado el que da una cierta imagen del presente; pues bien, para este derecho la historia personal, que es vida que se acumula, es tan importante, que dispone que "desfamando tortizeramente un ome a otro de tal yerro que si le fuesse provado deveria morir o ser desterrado para siempre porende, decimos que debe recebir esa mesma pena aquel que lo enfamó..." (ley $8^{\mathrm{a}}$ )

Por su parte, la ley $1^{2}$ nos dice que "fama es buen estado del ome, que bive derechamente e segund ley e buenas costumbres, non aviendo en si manzilla nin mala estanza. E disfamamiento tanto quiere dezir como profazamiento que es fecho contra la fama del ome..."

El Título VII, "De las falsedades", protege el bien de la veracidad, que es tan importante para la ordenada vida social, pues "una de las grandes maldades que puede ome aver en si, es fazer falsedad, ca della se siguen muchos males, e grandes daños a los omes" (Prólogo)

"Falsedad es mudamiento de la verdad. E puedese se fazer falsedad en muchas maneras" (ley $1^{3}$ ); ahora bien, como el valor de la veracidad es para este derecho sobremanera importante, castiga la falsedad con penas severas, que van desde el "ser destinado para siempre en alguna isla", "cortar la mano", en el caso del escribano de algún Consejo que "fiziere carta falsa", hasta la de muerte, en el caso del que "faze moneda falsa o cercena la buena" (leyes $6^{3}$ y $9^{a}$ ), como penas que afectan a la vida o la integridad física, amén de otras menores, que son multas.

El Título VIII, "De los omezillos", protege la vida física y como este bien es igualmente tenido en alta estima, la pena para quien lo comete es la de muerte; incluso "aquel que da armas a otro, sabiendo que quiere ferir o matar a alguno con ellas, o a si mismo, deve aver pena de omicida". (ley $10^{3}$ )

No obstante la materia de este título, la ley $11^{2}$ legisla sobre "el judgador que da falsa sentencia en pleyto de justicia", en la que el bien protegido es la verdad en juicio, pero en el que la sentencia es de muerte o desterramiento y dispone que "pena de omicida meresce el judgador que a sabiendas da falsa sentencia... judgando a muerte o a desterramiento o a perdimento de miembro, non lo meresciendo el. Essa mesma pena deve aver aquel que dixere falso testimonio en tal pleyto", agrega además esta severa disposición legal, y la razón es muy clara, ya que el juez puede matar injustamente por medio de una sentencia.

Por último, protegiendo la lealtad o solidaridad, que es expresión de fuertes vínculos interpersonales, que son elementos vivificadores de la vida social, la ley $16^{a}$ señala que "pena de omicida merescen los siervos e los sirvientes que ven matar a sus señores - los fijos dellos, e non los acorren".

El Título X, "De las fuerzas", en el que el bien protegido es la vida tranquila o pacífica, la ley $8^{2}$ dispone que "la pena que deve aver todo ome que fiziesse fuerza con armas... es que deve ser desterrado para siempre en alguna isla... mas si en la fuerza 
que alguno fiziesse tortizeramente con armas, fuesse muerto algun ome... debe morir, porque de qual parte quier que alguno muera, el fue en culpa de su muerte".

El Título XII, "De las treguas, e de las seguranzas e de las pazes" - instituciones típicamente medievales o caballerescas, en que el bien protegido es la paz-dispone que "los quebrantadores de la tregua... si fueren fijodalgos... pena de los rieptos (que es pena de muerte)... e si fueren otros omes de menor guisa... muera por ello".

La ley $1^{\text {BD }}$ dice que "tregua es un aseguramiento de se dan los fijodalgos entre si, unos a otros, después que son desafiados, que no se haga mal en los cuerpos, nin en los averes, en cuanto la tregua durare". Por su parte, en el Título III, ley $1^{\text {a }}$, se dice que "riepto es acusamiento que faze un hidalgo a otro por Corte, profazandolo de la trayción o del aleve que le fizo".

Con respecto a la paz, la ley $4^{a}$ dispone que "paz es fin e acabamiento de la discordia e del desamor" y que "quien quebrantare la paz despues que fuera puesta... deve aver aquella mesma pena que han aquellos que quebrantan la tregua...", es decir, pena de muerte.

EI Título XIV, "De los furtos...", protege la propiedad privada, o en términos vitales, la vida económica, que es lesionada por el hurto.

Asi, la ley $18^{a}$ dispone que "los furtadores pueden ser escarmentados en dos manera. La una es con pena de pecho. E la otra es con escarmiento que les fazen en los cuerpos... Más por razón de furto non deven matar, ni cortar miembro alguno. Fueras ende, si fuesse ladron conoscido... que oviesse entrado por fuerza en las casas, o en los lugares de otro, para robar con armas o sin armas... debe morir por ende el, e cuantos dieren ayuda e consejo a tales ladrones para fazer el furto o los encubrieren... deven aver aquella mesma pena", esto es, pena de muerte.

En este mismo título, la ley $22^{3}$ sanciona a quienes "furtan o sosacan los fijos o los siervos agenos", y "si el ladrón fuere fijodalgo, deve ser echado en fierros e condenado para siempre que lavore en las lavores del Rey. E si fuere otro ome, debe morir por ende."

El Título XVII, "De los adulterios", protege la vida matrimonial y así la ley $15^{a}$ dispone que "acusado seyendo algund ome, que oviesse fecho adulterio, si le fuesse provado que lo fizo, deve morir porende: mas la mujer que fiziesse adulterio, maguer le fuesse provado en juyizio, deve ser castigada e ferida publicamente con azotes e puesta e encerrada en algund monasterio de dueñas..."

El Título XVIII, "De los que yazen con sus parientas o con sus cuñadas", protege la vida familiar, la que considera perjudicada por estas relaciones y es así como la ley $3^{\text {a }}$ dice que "el que yoguiere con su parienta o con su cuñada... deve aver pena de adulterio", agregando que "Esta mesma pena... deve aver la mujer que a sabiendas fiziere este pecado".

Los Títulos XIX al XXII protegen la vida moral por lo que se refiere al sexo; es asi como el Título XIX, que legisla sobre "los que yazen con mugeres de orden, o con biuda que biva honestamente en su casa, o con virgenes... no les faziendo fuerza", en su ley $2^{a}$ dispone que "aquellos que... fazen pecado de luxuria con mugeres... si fuere ome honrado deve perder la mitad de todos sus bienes... si fuere ome vil deve ser azotado públicamente e desterrado en alguna isla por 5 años, pero si fuere siervo... deve 
ser quemado". En esta ley el bien protegido es la castidad, virtud moral pero no jurídica, cuya violación es tan severamente castigada.

El Título XX que legisla sobre "los que fuerzan o llevan robadas las virgenes, o las mugeres de orden, o las biudas que biven honestamente", dispone en su ley $3^{a}$ que quien incurriere en tales actos"... deve morir porende; e demás deven ser todos sus bienes de la muger que assi oviesse robada o forzada... e esas mesmas (pena) deven aver los que le ayudaron a sabiendas a robarla o a forzarla". En esta ley el bien protegido es la libertad sexual o la vida sexual ejercida con libertad, la que es atropellada por el delito de violación.

El Título XXI, "De los que fazen pecado de luxuria contra natura", dispone en su ley $2^{a}$ que "deve morir porende también el que lo faze, como el que lo consiente" el pecado de sodomía, agregando que "essa misma pena debe aver todo ome o toda muger que yoguiere con bestia". En esta ley el bien protegido es la vida sexual natural.

Por último el Título XXII, "De los alcahuetes", después de aclarar que "Leno, en latín, tanto quiere dezir en romance, como alcahuete, que engaña las mugeres, sosacando e faziendolas fazer maldad de sus cuerpos" (ley $1^{\mathrm{a}}$ ), dispone en la ley $2^{2}$ que "a los alcahuetes puede acusar cada uno del pueblo... e deven morir porende". En esta ley el bien protegido es, como en la ley $3^{a}$ del título XX, la libertad sexual, la que es vulnerada por el engaño, que hace prostituirse a la mujer.

El Título XXIII, "De los agoreros e de los sorteros, de los otros adévinos, e de los fechiceros e de los truhanes...", en su ley $2^{3}$ nos dice qué cosa es adevinanza: "adevinanza tanto quiere dezir como querer tomar el poder de Dios para saber las cosas que están por venir", y a los adevinos "acusar puede cada uno del pueblo..." e deven morir por ende" (ley $3^{2}$ ) El bien protegido por esta ley podemos decir que es la vida futura, la que puede ser manipulada por el adivino, convirtiendo al afectado en títere.

Los Títulos XXIV y XXV legislan sobre los judíos y los moros, respectivamente, los que son miembros de la comunidad castellana, pero son discriminados por fe y por raza de los castellanos, que son todos, al parecer, cristianos.

EI Título XXIV nos dice que "judíos son una manera de gente, que como quier que no creen la Fe de nuestro Señor Jesucristo..." "Onde, pues que en el título antes deste fablamos de los adevinos, e de los otros omes que dicen que saben las cosas que han de venir, que es como en manera de menospreciamiento de Dios, queriéndose igualar con El, en saber los sus fechos e las sus poridades: queremos aquí dezir de los judíos, que contradizen e denuestan el su nome, e el su fecho maravilloso e santo que el fizo, quando embio el su Fijo nuestro Señor Jesucristo en el mundo, para los pecadores salvar" (Prólogo)

La ley $2^{a}$ dispone que "mansamente e sinn bollicio deven fazer vida los judíos entre los christianos, guardando su ley e non diziendo mal de la Fe de nuestro Señor Jesucristo. Otrosi, se deven mucho guardar de predicar, nin convertir ningún christiano, que se torne judío... e qualquier que contra esto fiziere, debe morir..." Agrega esta ley que si los judios "fazen el dia del Viernes Santo remembranza de la Pasión de nuestro Señor Jesucristo, en manera de escarnio, furtando niños e poniéndolos en cruz... el Rey... develos mandar matar". El bien protegido por el primero de estos preceptos es la libertad de culto, aún cuando sin libertad de apostolado, y el segundo el respeto por la religión, en este caso la cristiana. 
La ley $6^{a}$., que legisla sobre el cambio de religión por el judío, dispone que "si algún judío o judía, de su grado se quisiere tornar christiano o christiana, non gelo deven embargar los otros judíos en ninguna manera. E si alguno de ellos lo apredreassen o firiessen o matassen... mandamos que todos aquellos matadores o aconsejadores de tal muerte o apedreamiento, sean quemados".

La ley $7^{2}$ por el contrario, con respecto al cambio de religión por el cristiano, "que se tornare judío... mandamos que lo maten por ello, assi como si se tornasse $\mathrm{He}-$ reje".

El bien protegido por estas dos últimas leyes es la verdadera religión, que se ha de encarnar en los hombres, según o con las atribuciones que la cultura de la época le otorga a las autoridad civil para defenderla.

Las leyes $9^{\mathrm{a}}$ y $10^{\mathrm{a}}$, por último, regulan las relaciones naturales entre judíos y cristianos. Así la primera, que se refiere al "judío que yaze con christiana", dispone que "todos los judíos, contra quienes fuere provado de aquí adelante que tal cosa ayan fecho, que mueran por ello", agregando que "la christiana que tal yerro fiziere, non tenemos por bien que fingue sin pena. E por ende mandamos... que aya aquella mesma pena que diximos en la postrimera ley en el título de los Moros, que debe aver la christiana que yoguiere con moro", esto es, pena de muerte a la segunda vez que lo haga.

La segunda, que se refiere a "los judíos que tienen christianos por siervos", dispone que "comprar, nin tener, non deven los judios por sus siervos ome nin muger que fuesse christiano, e si alguno contra esto fiziere... si el judio sopiese que lo era... debe el judío morir porende".

El Título XXV nos dice que "moros son una manera de gente que creen que Mahoma fue propheta e mandadero de Dios" (Prólogo). Ahora bien, las disposiciones que les son aplicables son las mismas que para los judíos, con la sola excepción que se refiere a la prohibición de que tengan siervos cristianos, que no existe para los moros.

El bien natural que la ley pretende en las leyes $9^{a}$ y $10^{a}$ de los judíos y la $10^{a}$ de los moros, es conservar la pureza de la sangre castellana, impidiendo su mezcla con la de judíos y moros, como también el que por esta relación se debilite la fe de los cristiano y se introduzcan herejías.

El Título XXVI, "De los herejes", no dice que "herejes son una manera de gente loca, que se trabajan de escatimar las palabras de nuestro Señor Jesucristo e le dan otro entendimiento contra aquel que los Santos Padres les dieron e que la Eglesia de Roma cree e manda guardar" (Prólogo), agregando en la ley $1^{\text {a }}$ que de "los herejes de qualquier manera que sean, viene muy grande daño a la tierra", para concluir, en ley $2^{3}$, que "los herejes pueden ser acusados de cada uno del pueblo delante de los Obispos o de sus vicarios... e si por aventura non se quisieren quitar de su porfía, devenlos judgar por herejes e darlos después a los Juezes seglares, e ellos devenles dar pena (de) quemar en fuego de manera que mueran."

El bien protegido es la ortodoxia, es la vida de fe según la entiende la autoridad de la Iglesia, que es el Papa, que mantiene la unidad de los cristianos, pues la herejía, que es "departimiento" o división, produce "muy grande daño a la tierra", no sólo en el aspecto religioso sino que también natural. 
El Título XXIX, "De como deven ser recabdados los presos", en su ley $11^{\text {a }}$ dice que como "muevense los omes a buscar mal los unos a los otros... dando algo encubiertamente a aquellos que los han en guarda, porque les den mal de comer, o a beber, e que les den malas prisiones, e que fagan mal en otras maneras muchas... E si algún carcelero o guardador de presos, maliciosamente se moviere a fazer contra lo que en esta ley es escrito, el Judgador del lugar lo debe fazer matar por ello."

El bien que esta ley protege es la vida del preso en la cárcel, o que el castigo no debe exceder de lo que dispone la sentencia del juez, por decisión del carcelero que no tiene autoridad para aumentarlo.

La ley $15^{a}$ dispone que "sin mandado del Rey... mandamos y defendemos que ninguno sea osado de fazer cárcel, si non tan solamente el Rey... E si otro fiziere cárcel por su autoridad, o cepo o cadena sin mandado del Rey, e metiesse omes en prisión en ella, mandamos que muera por ello." "Pero si algunos quisieren hazer cepos en sus casas para guardar sus moros cautivos, bien lo pueden fazer sin mandado del Rey...". Esta forma de excepción se explica en razón de la permanente guerra entre moros y cristianos, que se prolonga por casi 8 siglos, desde el 711 hasta 1492.

El bien protegido por esta ley es la seguridad de los presos y la posibilidad cierta de saber donde están para sus parientes y personas interesadas por ellos.

El Título XXX, "De los tormentos", nos dice que "Comenten los omes fazer grandes yerros e malos, encubiertamente, de manera que non pueden ser sabidos nin provados. E por ende tuvieron por bien los sabios antiguos que fiziessen tormentar a los omes, porque pudiessen saber la verdad ende dellos" (Prólogo). La ley $1^{a}$ nos dice que "tormento es una manera de prueba que fallaron los que fueron amadores de la justicia para escodriñar e saber la verdad por el, de los malos fechos que se fazen encubiertamente e non pueden ser sabidos nin provados de otra manera", pero, agrega la ley $4^{a}$ que "...si del tormento muriere o perdiere miembros por las feridas, deve el Judgador que lo mandó atormentar recebir otra tal pena como aquella que fizo dar a aquel, o mayor, catando la persona que fue assi atormentada, e la del Judgador que lo mandó assi fazer."

Aceptado el tormento como legitimo, como ocurre en esta ley, el bien protegido es la vida e integridad física del atormentado.

El Título XXXI, "De las penas" dispone en la ley $10^{\text {a }}$ que "el ome que es desterrado, si tornare a la tierra sin mandado del Rey, deve morir". El bien protegido por esta ley, que establece la pena más drástica, cual es la de muerte, es la paz de la comunidad, el bien más directamente común, el que ha sido tan gravemente perjudicado por un hombre que lo ha hecho acreedor a la pena de destierro, que sólo puede aplicar el Rey, según lo dispone la ley $5^{2}$ de este mismo título.

Al terminar este catálogo de delitos y de sus penas y alterando el orden hasta aquí seguido, nos referimos a la ley $6^{\mathrm{a}}$ de este título, que se refiere a "Quales penas son vedadas a los Judgadores, que las non manden dar" y asi nos dice que "... algunas maneras son de penas que las non deven dar a ningún ome, por yerro que aya fecho; así como señalar alguno en la cara quemándole con fuego caliente, o cortándole las narices, nin sacandole los ojos, nin dandole otra manera de pena en ella, de que finque señalado. Esto es porque la cara del ome fizo Dios a su semejanza; e por ende ningún Juez non deve penar en la cara, ante defendemos que lo non fagan. Ca Dios tanto lo 
quiso honrar e ennoblecer faziendolo a su semejanza, non es guisado que por yerro e por maldad de los malos, sea desfeada nin destorpada la figura del Señor".

Así entonces, el derecho de la Siete Partidas ve en la cara, aún del hombre más malo, el rostro del Señor.

Por último, El Título XXXIV, "De las reglas de derecho", en su regla $1^{\text {a }}$ que se titula "Como todos los judgadores deven ayudar a la libertad", dispone: "E dezimos, que regla es de derecho, que todos los Judgadores deven ayudar a la libertad, porque es amiga de la natura, que la aman non tan solamente los omes, más aún todos los otros animales".

Podemos finalizar este trabajo, en el que hemos analizado a Las Siete Partidas en la perspectiva de la vida, con dos conclusiones.

La Primera: Si nuestra lectura y comprensión de lo leído es superficial, como la frase e idea más repetida es "deve morir porende", podemos adquirir la impresión de que Las Siete Partidas no aprecia en mucho ni protege, por consiguiente, con un querer ser eficaz, el bien de la vida.

No podemos ni debemos caer en este error.

Las Siete Partidas tiene en la más alta estima la vida, la religiosa o sobrenatural y la natural y dentro de ésta la intelectual y la moral, como también la física o biológica, con la cual comienza, para el hombre, toda posible vida superior, pues ella señala el comienzo de su existencia.

Por esta alta apreciación de la vida es que Las Siete Partidas considera tan grave su injusta eliminación o degradación y castiga con la más pesada pena a quien, sin justificación alguna y con la intención de causar daño, la elimina o perjudica.

Lo que ocurre en nuestro tiempo es, por desgracia, exactamente lo contrario.

Si miramos a la legislación vigente, en casi todos los estados, en especial la de occidente, comprobamos que ya no penan, incluso despenalizan, más aún, favorecen a los autores de un delito atroz como es el aborto provocado directo, como también disminuyen las penas para otros homicidios y delitos; con respecto a la vida moral, nada o casi nada hace para evitar su creciente degradación; en cuanto a la vida intelectual, la deja entregada a la ley de la oferta y la demanda, que en este campo permite que triunfe el que menos potencie al entendimiento de los hombres; por lo que se refiere a la vida religiosa -el único aspecto positivo que vemos en ella- prescinde de considerarla en sus disposiciones, ya que lo sobrenatural pertenece a un nivel superior al civil o estatal.

Todo lo anterior muestra que hoy día, bajo una aparente alta apreciación de la vida, en el fondo no se la valora como se debiera, pues el derecho no castiga con severidad a quienes atenten en su contra, manifestando así su poco aprecio por ella.

En conclusión, Las Siete Partidas es un conjunto de normas de derecho que manifiestan un alto aprecio por la vida, en todas sus expresiones, y que procura defenderla de sus injustos agresores, castigándolos con la pena más dura, que es el modo jurídico de hacer sentir su valoración por ella. 
La Segunda: Las Siete Partidas -como todo derecho escrito que pasa a tener vigencia en fecha cierta y determinada- puede ser analizada en sus antecedentes que lo originaron y en sus efectos o influencia.

Con respecto a lo primero, Las Siete Partidas tiene como antecedentes toda la cultura anterior, siendo así ella una suerte de enciclopedia, en la que influyen el Antiguo y Nuevo Testamento, la filosofía griega, en particular la aristotélica, el derecho romano clásico, las opiniones de los padres de la Iglesia, las normas canónicas de la misma, el derecho hispanovisigodo y usos, costumbres y fueron medievales castellanos, por último.

Con respecto a lo segundo, que es lo que más nos interesa destacar, esto es, la influencia de Las Siete Partidas, afirmamos que su influencia ha sido extensa y profunda, por la aplicación preferente que de ella hicieron los tribunales de justicia, en atención a la perfección de su contenido, no obstante el lugar postergado en el que se le ubicó en el orden de prelación del derecho castellano.

Ahora bien, esta influencia -como ocurre con los grandes cuerpos juridicos- no se limita sólo al ámbito de los tribunales, sino que lo excede y pasa al general de la vida, que no es solamente de contienda entre partes y es así como este código formó la mentalidad del castellano medieval, incluso de aquel que al despuntar la modernidad, deja su tierra para iniciar la gran empresa que es extender a un nuevo continente la cultura castellana, "a servicio de Dios é á pro comunal de las gentes" (Partida I, Título $1^{\circ}$ ) 